\title{
CARACTERIZACIÓN DEL CLERO CATEDRALICIO CORDOBÉS DEL ANTIGUO RÉGIMEN
}

\author{
POR \\ SOLEDAD GÓMEZ NAVARRo
Universidad de Córdoba
}

\section{RESUMEN}

Reflexión sobre las funciones del clero regular de la catedral de Córdoba por medio de escrituras notariales de donación y fundación de los siglos XVII y XVIII.

\section{ABSTRACT}

Research on the regular clergy's functions of the Córdoba Cathedral by notarial deeds of gifts and foundation in the XVIIth and XVIIIth centuries.

\section{INTRODUCCIÓN}

Esta colaboración forma parte de amplio proyecto de investigación propio recién iniciado centrado en el estudio de la Iglesia de la España Moderna como estructura de poder. Habiendo dado ya algunos frutos ${ }^{1}$, y manifestándose primaria y genuinamente aquél en sus élites, aquí abordamos precisamente el exa-

I S. Gómez NaVarRo, «La orden concepcionista en Montilla (Córdoba). Fundación del convento de Santa Anay, La Orden Concepcionista. Actas del I Congreso Internacional, I, León, 1990, pp. 261274; «Movimiento fundacional en la Córdoba del último cuarto del siglo XVI», V Reunión Cientifica de la Asociación Española de Historia Moderna, I: Felipe II y su tiempo, Cádiz, 1999, pp. 473-478.

Actas del I Congreso de Kistoria de la Iglesia y el Mundo Hispánico Hispania Sacra, 52 (2000) 
men de uno de sus más significados y significativos agregados sociales, como asimismo en otras ocasiones ya hicimos aunque para ámbito historiográfico distinto ${ }^{2}$.

Para esta ocasión analizamos donaciones y fundaciones como tales escrituras notariales sueltas - ocho desde fines del seiscientos y hasta casi fines del setecientos--, para acercarnos al conocimiento del cabildo catedralicio cordobés a través de la imagen o perfil que éste en aquéllas proyecta. Este sería el objetivo y la cuestión.

\section{Mimbres para el Retrato} tierro.

El personal del cabildo catedralicio cordobés se ocupa de su capilla y en-

Es el caso del Racionero D. Mateo de San Llorente y Alfaro y de su madre, $D^{2}$ Catalina de Alfaro, viuda de un jurado del regimiento de la ciudad, quienes reciben de los religiosos del francisco convento de San Pedro el Real adjudicación de aquél -sepultura- en la capilla de Nuestra Señora de la Pura y Limpia Concepción de María de dicho cenobio, con todo su suelo, altar y retablo, para sí y sus sucesores. Dándoles la "cuasi posesión y el ius cediendi et sepeliendi» como es habitual en estos gestos ${ }^{3}$, colocarían asimismo una cabeza de Ecce Homo que estaba en la sacristía, al que dotaban de urna con sus cristales y lámpara de aceite para perpetuamente alumbrarse; celebrarian a honor de Dios Nuestro Seffor y su bendita Madre «y que las ánimas de purgatorio gocen de los sufragios divinos de que necesitan ${ }^{4}$, asimismo siempre cuatro misas anuales cantadas por la comunidad del convento, una en el segundo viernes de marzo, otra en el día de San Pedro, otra en el de Santa Catalina, y otra más el día de los difuntos; y aceptarían, previo compromiso de unas casas de los otorgantes, mantener la dicha capilla, labrada, enhiesta y reparada de todo lo necesario, con la decencia y el cuidado obligados.

\footnotetext{
2 S. GómEZ NaVARRo, «Un ensayo de microanálisis social: los escribanos cordobeses ante la muerte (1690-1833)m, en La Burguesta espariola en la Edad Moderna, II, Valladolid, 1996, pp. 1071-1087; «Élites locales ante la vida y la muerte, Córdoba, 1650-1833. Apuesta de trabajo y primeras aportaciones», en Monarquia, imperio y pueblos en la España Moderna, 1, Alicante, 1997, pp. 179-187; «Personal del Santo Oficio en la provincia de Córdoba: modos de vida y mentalidad», Estrudios sobre Iglesia y saciedad en Andalucia en la Edad Moderna, Granada, 1999, pp. 51-57.

3 Archivo de Protocolos Notariales de Córdoba-APNCO en lo sucesivo, hoy entre los fondos del Archivo Histórico Provincial; primera cifra, oficio; segunda, protocolo; anto entre paréntesis; digitos finales, folios-, 35, p. 49 (1700), 46-53r., f 49v: Adjudicación de capilla y entierro.

4 lbid., $\mathrm{f}^{0} 50 \mathrm{v}$.
} 
Otras veces se ocupa de cristianos cautivos:

Es el caso del Prebendado D. Juan Ignacio de Fuentes, quien dona unas casas principales en la villa de Arjona, una haza de dos fanegas de tierra calma, y un parrizal -sic- de viña con diez estacas de una fanega y un celemín de tierra, bienes todos ellos de su propiedad, a la obra pía de Redención de Cristianos Cautivos del trinitario convento de Andújar, para que lo procedido de su arrendamiento se destine a ese fin mas con la precisa condición de que, para la libertad, prefieran a los que sean vecinos de la ciudad de Córdoba y su obispado 5 .

Asimismo se acuerda de indigentes y necesitados:

El igualmente Prebendado D. Rodrigo de Cotta Castillejo y Cabrera donaba el capital y réditos de un censo de ciento veinte reales de principal que le pertenecía a obra pía del hospital de la Misericordia de Córdoba para ayuda y asistencia a sus pobres enfermos, cuyo Patronazgo ejercia el mismo Cabildo de la Catedral ${ }^{6}$.

Se acordaban también de imágenes sagradas de su devoción:

El presbítero, notario del Santo Oficio de la Inquisición, y capellán perpetuo y organista de la Catedral D. Diego de Quesada y Castilla legó un pectoral de plata a San Agustín, en el convento de su mismo nombre, «por el mucho fervor que siempre le ha tenido" ${ }^{7}$, a cambio del cumplimiento por citada comunidad agustina de su tradicional hora de oración el día de San Francisco de Paula.

Igualmente de comunidades religiosas femeninas:

El Prebendado D. Alonso de Burgos dotaba una lámpara para que perpetuamente ardiera en la capilla que en el cordobés convento de carmelitas descalzas de Santa Ana le pertenecía, otorgando para tal fin, y como su dotación, cien ducados vellón de principal; así como la fundación de memoria perpetua, asimismo en dicho convento, de dos misas cantadas de réquiem con sus aniversarios, una en el día de la conmemoración de los difuntos o en el siguiente, otra en el día en que muriere el otorgante, entregando para este segundo objeto otros tantos cien ducados de principal ${ }^{8}$.

De sus mismos correligionarios:

El Racionero entero D. Raimundo Alfonso García del Olmo fundaba así un aniversario perpetuo que se habría de celebrar por el ilustre cabildo de la insigne mayor colegial iglesia de Santa María de Úbeda a que el otorgante había pertenecido como canónigo, el día que se reza el de San Raimundo de Peñafort,

\footnotetext{
5 APNCO, 30, p. 379 (1740), 94-96v.: Donación.

6 APNCO, 4, p. 206 (1760), 763-766v.: Su Donación.

7 APNCO, 11, p. 83 (1710), 16-19r., f 16r.: Donación de un pectoral de plata a San Agustín.

- APNCO, 29, p. 89 (1690), 34-38v: Obligación de Fundación de Memoria.
} 
santo de su nombre. Bajo el mismo citado cabildo como su patrono, se compondría, en su víspera y después de completas, de una vigilia cantada y nocturno, y al final un responso; y en el referido día de la fiesta, de una misa de réquiem con otro responso'.

$\mathrm{Y}$ tampoco olvidaban sus propios bienes en forma de vínculos, mayorazgos y capellanías:

El Prebendado D. Antonio Camacho de Pedrajas fundaba de esta forma tres vínculos y mayorazgos en cabeza de una sobrina, comprometiéndola, a ésta y sus sucesores, al cumplimiento de doce misas rezadas anuales perpetuamente en la parroquial de Montoro, de donde era natural. Extinguidas las líneas que nombraba, seffalaba por «heredero de los bienes de los tres mayorazgos que llevo fundados» a una obra pía instituida por su tío D. Fernando Camacho, igualmente presbítero, para que todos los bienes quedaran unidos y juntos en un solo vínculo o mayorazgos ${ }^{10}$. Determinaba asimismo que si los vínculos recaían en citada obra pía, sus patronos dieran perpetuamente quince dotes anuales de a treinta ducados cada una a doncellas huérfanas de Montoro, prefiriendo a sus parientes pobres para ello; y que, cumplidas todas las cargas, el residuo que quedara en aquélla se repartiera por los patronos en limosna a pobres de Montoro prefiriendo a los parientes pobres.

En el mismo año fundaba el mismo D. Antonio también una capellanía perpetua para que se sirviera en la ermita de San Fernando, sita en el pago de la Nava, término de Montoro, sobre una heredad de olivar con su casa, pila, demás peltrechos, y varios centenares de pies de olivos, valorado todo en más de veintiocho mil reales de vellón. Sería para que sus poseedores, aunque pequeños, la tuvieran y pudieran alimentarse, criarse y educarse con su renta hasta los veinticinco años, momento en que se ordenarían sacerdotes; y para que se dijera por su alma e intención cincuenta misas rezadas en la mencionada ermita de San Fernando, los domingos y fiestas de guardar; una más el día de San Sebastián; y otra más en el de San José ${ }^{11}$.

\section{El Retrato}

En sus relaciones familiares, sociales, modos de vida, bases económicas, niveles de alfabetización y cultura, religiosidad y actitud ante la muerte, origen y ubicación en la ciudad, que es como también lo entregan las escrituras de

9 APNCO, 4, p. 226 (1780), 692-693v.: Fundación para un aniversario perpetuo.

10 APNCO, 4, p. $206(1760)$, 480-502r., $f^{\circ} 497$ r.: Fundación de tres vínculos y mayorazgos.

11 APNCO, 26, p. 58 (1760), 85-91r.: Fundación de Capellanía. 
donaciones y fundaciones, éstas presentan un clero catedralicio para la Córdoba moderna marcado por:

1. Entronque familiar de prosapia: Cuando consta, parentesco con jurados, personal del Santo Oficio, eclesiásticos, etc. Asimismo, vinculación a barrios destacados de la ciudad, como es, aun cuando en este caso por razones obvias, Santa María o el Sagrario de la misma Catedral.

2. Relación posición clerical-interés por el gesto, de manera que mayor participación en éste por los más encumbrados o elevados eclesiásticamente.

3. Presencia de la propiedad: Como indispensable aval de las decisiones adoptadas, aquí están por eso capillas privadas, títulos, bienes inmuebles, vinculaciones, oficios, censos...

4. Solidaridad familiar: No sólo se recuerdan e incorporan padres, hermanos, sobrinos, ascendientes y descendientes en el intangible beneficio espiritual del más allá, sino que están absoluta y perpetuamente presentes en el material y más tangible de atenciones, cuidados y desvelos.

5. Religiosidad tradicional: Entre otros objetos -las abundantes misas por ejemplo-, por eso aquí santoral, ánimas del purgatorio, Inmaculada Concepción de Marfa sobre todo.

6. Ejemplificación, moralismo o didactismo, transido de la más pura y recia tradición: Preocupación por el desvalido, alma, religiosidad, muerte y transcendencia.

7. Cumplimiento de su rol en la comunidad: Indicando, señalando, marcando pautas -distribución de riqueza, petición de misas, atención al menesteroso...-, precisamente manifiestan o demuestran lo anterior.

8. Y sin olvidar obviamente a los demás, sobre todo preocupación de o por sí. Situados de esta forma ante sí-también ante los otros como decimos-, especialmente es siempre la propia alma, la búsqueda de la memoria de sí, de la notoriedad, la promoción, aun la preeminencia y la ostentación. 